\title{
The role of estrogen deprivation therapy in premenopausal women with primary unresectable intracardiac leiomyomatosis: a systematic review and meta-analysis
}

\author{
Jinxiao Liang ${ }^{1 \dagger}$, Ruilin Lei ${ }^{1 \dagger}$, Mingwei Xie ${ }^{2}$, Shaodan Lin ${ }^{1}$, Jing Xu' ${ }^{1}$ Xiaoting Ling ${ }^{1 *}$ and Qingsheng Xie ${ }^{1 *}(\mathbb{C}$
}

\begin{abstract}
Background: Intracardiac leiomyomatosis (ICLM) is a rare life-threatening form of intravenous leiomyomatosis (IVLM). The incomplete resection and recurrence are associated with high morbidity and mortality. The objective of this study is to identify that whether estrogen deprivation therapies, including bilateral salpingo-oophorectomy (BSO)-based surgery and gonadotrophin releasing hormone agonists ( $\mathrm{GnRHa}$ ) administration, could bring benefits to patients with primary unresectable ICLM.
\end{abstract}

Methods: PubMed/MEDLINE (Ovid) was searched (up to May 2021) for studies reporting individual patient data on demographics, clinicopathological features, treatment, and follow-up information. Exclusion criteria were patients who may have been included in two or more publications. This study was performed in accordance with the Preferred Reporting Items for Systematic Reviews and Meta-Analyses (PRISMA) guidelines.

Results: A total of 114 patients from 70 papers were included. Several reports showed that the tumor in the right atrium and inferior vena cava shrank dramatically after BSO-based surgery, or GnRHa administrated preoperatively in premenopausal women. The rate of complete resection was $64.04 \%$ in patients with ICLM, which was $85.25 \%$ in no/slight adhesion and no pulmonary nodules group, while $22.22 \%$ in firm/extensive adhesion and/or pulmonary nodules group ( $p<0.0001)$. Meanwhile, the recurrence rates in patients with complete resection and incomplete resection were $4.29 \%$ and $37.84 \%$ respectively $(p<0.0001)$. Furthermore, complete resection with BSO had the lowest recurrence rate of $3.13 \%$, incomplete resection with BSO had a progression rate of $45.45 \%$, while incomplete resection with ovarian preservation had the highest progression rate of $75.00 \%$.

Conclusions: The recurrence rate of ICLM was closely related to firm/extensive adhesion in IVC or above, and/or pulmonary nodules. BSO-based surgery might reduce the recurrence rate no matter ICLM could be completely resected or not. In addition, estrogen deprivation therapies could decrease tumor burden as a primary treatment, and further make a secondary complete resection feasible in premenopausal women with initially unresectable ICLM.

\footnotetext{
*Correspondence: lingxt@126.com; qingshengxie@126.com

${ }^{+}$Jinxiao Liang and Ruilin Lei contributed equally to this work

1 Department of Gynecological Oncology, Sun Yat-Sen Memorial Hospital,

Sun Yat-Sen University, 107 Yan Jiang Rd West, Guangzhou 510120,

People's Republic of China

Full list of author information is available at the end of the article
}

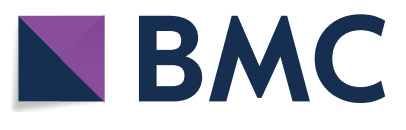

(c) The Author(s) 2021. Open Access This article is licensed under a Creative Commons Attribution 4.0 International License, which permits use, sharing, adaptation, distribution and reproduction in any medium or format, as long as you give appropriate credit to the original author(s) and the source, provide a link to the Creative Commons licence, and indicate if changes were made. The images or other third party material in this article are included in the article's Creative Commons licence, unless indicated otherwise in a credit line to the material. If material is not included in the article's Creative Commons licence and your intended use is not permitted by statutory regulation or exceeds the permitted use, you will need to obtain permission directly from the copyright holder. To view a copy of this licence, visit http://creativecommons.org/licenses/by/4.0/. The Creative Commons Public Domain Dedication waiver (http://creativeco mmons.org/publicdomain/zero/1.0/) applies to the data made available in this article, unless otherwise stated in a credit line to the data. 
Keywords: Intracardiac leiomyomatosis, Estrogen deprivation therapy, Primary treatment, Bilateral salpingooophorectomy, Gonadotrophin releasing hormone agonists

\section{Background}

Intravenous leiomyomatosis (IVLM) is an uncommon smooth muscle tumor that arises from either a uterine-related myoma or the intrauterine vessel walls and extends into the veins $[1,2]$. Under a rare condition, it reaches the right atrium by an extensive spread beyond the inferior vena cava (IVC), which is known as intracardiac leiomyomatosis (ICLM) [3]. ICLM is histologically benign but clinically aggressive, which can cause fatalities by acute heart or other organs' failure [3-6], surgical complications such as uncontrolled hemorrhage $[7,8]$, and recurrence [9-11].

Treatment for ICLM varied because of its rarity and complexity, which included surgeries [12-14], anti-estrogen hormone therapies $[9,12,15]$, and even a wait-andsee strategy $[1,16]$. Complete tumor resection was the most recommended $[17,18]$, but sometimes it cannot be achieved due to the high risks of surgery $[5,7,13,15,16$, 19-22], patient's poor conditions [4, 12, 23, 24], lack of medical resources [25], financial constraints [2, 26], or patients' refusal $[27,28]$.

Since ICLM is believed to be estrogen-dependent [1, 2], if the primary complete removal cannot be achieved, could the estrogen deprivation therapy be an initial choice? And could it facilitate a secondary complete resection? Therefore, a systematic literature review and meta-analysis of published patient data was conducted to investigate the feasibility of estrogen deprivation therapies, such as BSO-based surgery and GnRHa administration as the initial treatment of ICLM.

\section{Methods}

\section{Search strategy}

A literature search was performed through PubMed/ MEDLINE (Ovid) up to May 2021. The following search terms were used: "intracardiac leiomyomatosis", "leiomyomatosis extending to right heart" and "leiomyomatosis with cardiac extension". Two independent investigators screened all studies according to the inclusion and exclusion criteria. In case of disagreement, consensus was met by the senior researcher (Additional file 1: Figure S1). Other publications were found through reference lists of reviewed articles. All the enrolled articles were written in English title and abstract.

\section{Study selection and data extraction}

Studies were eligible if they provided individual patient data on demographics, clinicopathological features, treatment, and follow-up information. Patients were excluded from meta-analysis if any of the following criteria were met: (1) articles written not in English, (2) no specification of treatments, (3) no specification of follow-up data, and (4) pathology findings shown malignant results such as intravenous low-grade endometrial stromal sarcoma. Included case reports and case series were evaluated to assess whether clinicopathological features were provided, specified whether the intravenous leiomyomatosis involved heart. Data of demographics, clinicopathological features, treatment, and follow-up information were extracted by our two independent researchers following the predefined spreadsheet on individual patient level.

\section{Statistical analysis and quality assessment}

All the statistical analysis was performed using SPSS software, version 13.0 (SPSS Inc., Chicago, IL, USA). Associations between the clinicopathological features and the outcomes were examined using chi-square or Fisher's exact test. All tests were 2 -tailed with $p$ values $<0.05$ considered significant.

Murad et al. provided an approach to evaluate the quality of case reports and case series based on four components: selection, ascertainment, causality and reporting, resulting in a score with a maximum of 5 for both case series and case reports (Additional file 2: Table S1) [29]. There were 2 and 3 of the 8 binary questions not suitable for the case series and case reports, respectively. Quality assessment were evaluated by two independent investigators.

\section{Results}

\section{Systematic search and study quality}

Database search and reference lists identified 241 publications after removal of duplicates (Additional file 1: Figure S1). 109 publications were excluded after screening the titles and abstracts. 132 articles were reviewed and from which 62 were excluded following the inclusion and exclusion criteria. Finally, 70 studies with a total of 114 cases met these criteria in our meta-analysis (Additional file 2: Table S2). 12 studies were case series and 58 studies were case reports, which were published between 1975 and 2021.

Quality assessment identified acceptable study quality with $12(100 \%)$ case series and $48(82.76 \%)$ case reports scoring 4 points or higher in the modified quality evaluation by Murad et al. (Additional file 2: Table S1) [29]. 


\section{Clinicopathological features}

The clinicopathological features were showed in Table 1. The median age was 46.5 years (range: 24-72 years). The gynecological symptoms that were reported included pelvic pain, menorrhagia, and abdominal discomfort. The cardiopulmonary symptoms that were reported included syncope, dyspnea, chest distress, and lower-extremity edema. The BSO rate in patients admitted by the Department of Obstetrics and Gynecology was $93.33 \%$ (28/30), while the BSO rate in patients admitted by Department of Cardio-Thoracic Surgery or other departments was much lower $(65.31 \%$,

Table 1 Demographic, clinical and treatment factors of 114 reviewed cases of intracardiac leiomyomatosis

\begin{tabular}{|c|c|c|}
\hline \multirow[t]{2}{*}{ Item } & \multicolumn{2}{|l|}{ Case } \\
\hline & Number & Percent (\%) \\
\hline Total number of cases & 114 & \\
\hline Median age in years (range) & $46.5(24-72)$ & \\
\hline Publication Year & 114 & \\
\hline Within last 10 years & 72 & 63.16 \\
\hline Earlier than 10 years ago & 42 & 36.84 \\
\hline Presenting symptoms ${ }^{1}$ & 102 & \\
\hline Gynecological symptoms & 15 & 14.71 \\
\hline Cardiopulmonary symptoms & 56 & 54.90 \\
\hline Both gynecological and cardiopulmonary symptoms & 12 & 11.76 \\
\hline Without symptoms & 19 & 18.63 \\
\hline Menopausal status & 114 & \\
\hline Premenopausal or younger than 50 years old & 85 & 74.56 \\
\hline Postmenopausal or older than 50 years old & 29 & 25.44 \\
\hline Pathological features & 114 & \\
\hline Benign leiomyoma & 107 & 93.86 \\
\hline Atypical histologic features & 3 & 2.63 \\
\hline Unknown & 4 & 3.51 \\
\hline Treatment & 114 & \\
\hline Incomplete excision & 37 & 32.46 \\
\hline Complete excision & 73 & 64.04 \\
\hline Unknown & 2 & 1.75 \\
\hline Died perioperatively ${ }^{2}$ & 2 & 1.75 \\
\hline Admitted by which departments ${ }^{1}$ & 94 & \\
\hline Department of Cardio-Thoracic Surgery & 58 & 61.70 \\
\hline Department of Obstetrics and Gynaecology & 32 & 34.04 \\
\hline Other Departments ${ }^{3}$ & 4 & 4.26 \\
\hline Records with BSO or Ovarian Preservation ${ }^{1}$ & 79 & \\
\hline Admitted by Department of Obstetrics and Gynaecology & 30 & \\
\hline With BSO & 28 & 93.33 \\
\hline Ovarian Preservation & 2 & 6.67 \\
\hline Admittedby Department of Cardio-Thoracic Surgery or other Departments & 49 & \\
\hline With BSO & 32 & 65.31 \\
\hline Ovarian Preservation & 17 & 34.69 \\
\hline $\begin{array}{l}\text { Status of Adhesion at the level of IVC or above (ALIA), Status of pulmonary nod- } \\
\text { ules (PN) }\end{array}$ & 114 & \\
\hline Firm/extensive ALIA, and/or PN & 27 & 23.68 \\
\hline No/slight ALIA, no PN & 61 & 53.51 \\
\hline Unknown & 26 & 21.81 \\
\hline
\end{tabular}

The significance of bold highlight the number of cases in each group or subgroup

${ }^{1}$ available data less than $114{ }^{2}$ one died preoperatively, one died postoperatively; ${ }^{3}$ three were admitted by Emergency Department and one were admitted by Department of Gastrointestinal Surgery 
32/49, $p=0.0059)$. In addition, death associated with ICLM was reported in 3 patients. One died immediately after being admitted to the hospital without surgery [3], one died during surgery [7], and one died of multiple organ failure secondary to tumor progression 11 years after her diagnosis [5]. No leiomyoma embolizing the lung during or after surgery as a tumor thrombosis was reported. 3 patients with atypical histologic features for their ICLM could not achieve complete resection and two of them had a tumor regrowth postoperatively [1, $19,24]$.

\section{Adhesion situation, pulmonary involvement, and complete resection}

The total incomplete resection rate was $32.46 \%$ (37 out of 114). Among 114 patients, 27 (23.68\%) were reported to have firm/extensive adhesion in IVC or above, and/ or had lung metastasis, while $61(53.51 \%)$ had no or only slight adhesion in IVC or above without pulmonary nodules. $26(21.81 \%)$ reported no details. As shown in Table 2, the complete resection rate in no/ slight adhesion group was significantly higher than that in firm/extensive adhesion group $(p<0.0001)$. The gentle downward extraction via venotomy of the iliac /IVC veins even without sternotomy could be performed successfully in patients had no/slight adhesion and had no pulmonary nodules $[30,31]$. In contrast, the intracaval tumor of some patients were failed to be pulled out due to firmly adhesion [7, 14, 19, 20]. And torn traction in the IVC occurred in one of them, leading to severe bleeding and death during operation [7].

\section{Surgical procedure and prognosis}

The details of surgical process and follow-ups were reported in 107 patients. The mean follow-up interval was 30.55 months. Totally 17 (15.89\%) women underwent recurrence or regrowth of the residual tumor. More recurrence or regrowth of the residual tumors was found

Table 2 The complete resection rates between two groups with different adhesion situation and pulmonary involvement

\begin{tabular}{lccc}
\hline & $\begin{array}{l}\text { Complete } \\
\text { resection }\end{array}$ & $\begin{array}{l}\text { Incomplete } \\
\text { resection }\end{array}$ & $\boldsymbol{P}^{\#}$ \\
\hline $\begin{array}{l}\text { No/slight } \\
\text { adhesion and } \\
\text { no pulmonary } \\
\text { nodules }\end{array}$ & $52(85.25 \%)$ & $9(14.75 \%)$ & $<0.0001$ \\
$\begin{array}{l}\text { Firm adhesion } \\
\text { and/or pulmo- } \\
\text { nary nodules }\end{array}$ & $6(22.22 \%)$ & $21(77.78 \%)$ & \\
\hline
\end{tabular}

Valid patient's numbers: 88 ; \#The P-value was determined using the chi-square test in patients with incomplete resections and/or unresectable pulmonary nodules (median follow-up: 26.27 months, range from 2 to 120 months) than in those with complete resection (median follow-up: 32.73 months, range from 1 to 168 months) (37.84\% vs. $4.29 \%, P<0.0001$, Table 3 ). Furthermore, there were 26 women reported with a follow-up interval more than 48 months (48-144 months), and the recurrence rates were $60.00 \%$ (6 out of 10 ) and $12.50 \%$ ( 2 out of 16 ) between incomplete-resection and complete-resection patients ( $p=0.0256$, Additional file 2 : Table S4), respectively.

Among these 107 patients, reports on whether BSO was performed or not was found in 71 women who were premenopausal or younger than 50 years old (Table 4). Data demonstrated that patients with complete resection and $\mathrm{BSO}$ had the best prognosis, only 3.13\% occurred with tumor recurrence after surgery. Incomplete tumor resection with $\mathrm{BSO}$ had a progression rate of $45.45 \%$, while patients with incomplete resection with ovarian preservation had the highest rate of residual tumor regrowth $(75.00 \%)$. However, if complete tumor resection can be achieved, patients with ovarian preservation still had an acceptable recurrence rate of $15.38 \%$.

\section{Pre/postoperative GnRHa and ICLM}

GnRHa is extremely efficient and widely used to reduce tumor volume and reverse the related symptomatology for premenopausal women with uterine fibroids [32]. However, the tumors tend to return to their pretreatment size around 6 months after discontinuing treatment. And this phenomenon was also observed in our study. There were 8 women who received GnRHa pre or postoperatively and in the details were reported (Additional file 2: Table S5). All of them were premenopausal, either had no complete resection or later emerged with recurrence. The residual tumor was partly reduced in 3 patients with preoperative GnRHa administration initially [19, 33, 34], but the effects were limited and the tumor increased in size later soon. 3 patients had ovarian preservation and administration of GnRHa postoperatively (15 to 24 months), and the tumors were effectively suppressed or disappeared during the treatment $[9,15,35]$. The other

Table 3 The rates of residual tumor regrowth between two groups with complete or incomplete resection

\begin{tabular}{lcll}
\hline & $\begin{array}{l}\text { Recurrence or } \\
\text { regrowth }(\mathbf{n}=\mathbf{1 4})\end{array}$ & $\begin{array}{l}\text { No } \\
\text { progression } \\
(\mathbf{n = 6 8 )}\end{array}$ & $\boldsymbol{P}^{\#}$ \\
\hline $\begin{array}{l}\text { Complete resection } \\
\text { Incomplete resection }\end{array}$ & $3(4.29 \%)$ & $67(95.71 \%)$ & $<0.0001$ \\
\hline
\end{tabular}

Valid patient's numbers: $107 ;{ }^{\#}$ The $P$-value was determined using the chi-square test 
Table 4 Different treatments and residual tumor progression in premenopausal women with ICLM

\begin{tabular}{|c|c|c|c|}
\hline \multicolumn{2}{|c|}{ Complete resection (13) } & \multicolumn{2}{|c|}{ Incomplete resection (4) } \\
\hline Progression & No progression & Progression & No progression \\
\hline \multicolumn{4}{|c|}{ Ovarian Preservation (17) } \\
\hline $2(15.38 \%)$ & $11(84.62 \%)$ & $3(75.00 \%)$ & $1(25.00 \%)$ \\
\hline \multicolumn{2}{|c|}{ Complete resection (32) } & \multicolumn{2}{|c|}{ Incomplete resection (22) } \\
\hline Progression & No progression & Progression & No progression \\
\hline \multicolumn{4}{|l|}{$\mathrm{BSO}(54)$} \\
\hline $1(3.13 \%)$ & $31(96.88 \%)$ & $10(45.45 \%)$ & $12(54.55 \%)$ \\
\hline
\end{tabular}

Valid patient's numbers: 71; BSO: Bilateral salpingo-oophorectomy

2 patients had received incomplete resection with BSO and the administration of GnRHa postoperatively, the residual tumors remained stable [36, 37].

\section{Discussion}

ICLM is a rather rare pathologic condition and usually occurs among premenopausal women with a history of uterine leiomyoma. All the patients in this study were treated in enhanced or maximal-resource countries or areas. Patients tended to be well-treated, which at least partly lead to survivorship bias. Consequently, the incidence and the recurrence rate, the morbidity, and mortality in the whole world could be higher [38]. Moreover, it still remains controversial on the treatment strategy for the patients with ICLM, especially for those in developing areas or with less medical insurance, who may face unaffordable medical expenses and the shortage of medical resources [2, 26, 39]. Therefore, Li et al. emphasized that less invasive surgery without compromising the curative effect would be the main goal [39].

Complete removal of the ICLM plus BSO was the most optimal and efficient treatment in preventing recurrences (Table 4), which was consistent with other studies $[17,18$, $23,38,40]$. And the patients with complete-resection had a pronouncedly lower rate of recurrence when compared with that in those with incomplete-resection (Table 3).

However, complete resection cannot be performed in many cases for extension of tumors [5, 24, 27, 37], densely adherent to the luminal wall $[4,5,7,13-16,19-22,41$, $42]$, and patients' will $[27,28]$, or constrained medical resources. In such conditions, recurrence occurred postoperatively $[4,9,10,12,15,21,22,24]$, lethal complications such as uncontrolled hemorrhage [20, 42], heart failure, and sudden death happened [3, 7]. The complete resection rate was significantly lower in patients with firm/extensive adhesion than that in those with no/slight adhesion of IVC or above (Table 2). Among patients with incomplete resection, $37.84 \%$ had recurrence, which was significantly higher when compared with $4.29 \%$ in those with complete resection (Table 3). Correspondingly, with a longer follow-up interval, the recurrence rate was dramatically higher of $60.00 \%$ and $12.50 \%$ respectively (Additional file 2: Table S4). Therefore, it is a dilemma whether to suspend a high-risk surgery which may lead to incomplete resection and recurrence, or perform a complete resection which might be life-threatening.

Despite limited data, our research showed that the 15 patients tested by IHC were all positive for ER and/ or PR (Additional file 2: Table S3), which means it could be useful for the patients with ICLM to be treated with hormone-based therapies. Consistently, a premenopausal case showed that incomplete resection but BSO-based surgery could render the residual tumor reduced significantly postoperatively [34]. In another case, the unresectable IVLM shrank significantly by 9 months of GnRHa therapy, which could be completely removal thereafter [43]. GnRHa given pre or postoperatively in premenopausal women was shown to be able to reduce preoperative tumors size, and suppress the progression of the residual tumor $[9,15,19,33,34,36,37]$. Moreover, the intraoperative blood loss and medical costs was 7.5 and 7 times higher in patients with ICLM when compared with patients with IVLM but not extended beyond the abdominal cavity [18]. So, the application of estrogen deprivation therapies before the surgery might efficiently reduce the perioperative complications, and could further facilitate a secondary complete resection in premenopausal women. On the other hand, if the complete tumor resection cannot be achieved, ovarian preservation could lead to a notably high recurrence rate of $75.00 \%$ (Table 4). Therefore, whether complete resection could be accomplished or not, the estrogen deprivation therapies would be beneficial for treating the ICLM, especially when which was highly risky for completely resection, in the premenopausal women (Table 4, Additional file 2: Table S5). 
One other point worth emphasizing was that, patients admitted by the department of Thoracic and Cardiovascular Surgery or other departments had a significantly lower rate of BSO when compared to those patients admitted by the department of Obstetrics and Gynecology (Table 1). Considering the benefit brought by the $\mathrm{BSO}$, gynecologists should be involved in the treatment decision-making process of ICLM.

However, this meta-analysis has several limitations because all studies analyzed were observational with risks of bias. Potential bias was attempted to be minimized by excluding studies which failed to provide patient characteristics and follow-up information. The effects of estrogen deprivation therapies for ICLM were observed in not long follow-up intervals, and the data size was small due to the scarcity of this disease. Moreover, though most of the ICLM was found to have positive expression of estrogen receptor, antiestrogen therapy might be less beneficial in postmenopausal than in premenopausal women [44]. Further studies are needed to evaluate the rate of secondary complete resection, the long-term effects of estrogen deprivation therapy and the differences between the premenopausal women and the postmenopausal women.

\section{Conclusions}

Estrogen deprivation therapies may be essential in treating primary unresectable ICLM for its effects in shrinking the tumor size, suppressing the tumor progression, and facilitating a secondary complete resection. In other words, estrogen deprivation therapies could render a less invasive secondary surgery but without compromising the curative effect.

\section{Abbreviations}

ICLM: Intracardiac leiomyomatosis; IVLM: Intravenous leiomyomatosis; BSO: Bilateral salpingo-oophorectomy; GnRHa: Gonadotrophin releasing hormone agonists; PRISMA: Preferred reporting items for systematic reviews and metaanalyses; IVC: Inferior vena cava; IHC: Immunohistochemistry; ER: Estrogen receptor; PR: Progesterone receptor.

\section{Supplementary Information}

The online version contains supplementary material available at https://doi. org/10.1186/s13023-021-02087-7.

Additional file 1: Figure S1: PRISMA flow diagram outlining study selection. Data searches were performed up to June 2021.

Additional file 2: Supplemental material to support the methods and results.

\section{Acknowledgements}

Not applicable.

\section{Authors' contributions}

$\mathrm{J}$ : conceptualization, data collection and investigation, writing original draft, critical revision. RL: methodology, assisted in the conceptualization, formal analysis, contributed to the draft writing. MX: software, imaging analysis and the related draft revision, review and editing. SL: contributed to the methodology, writing and data curation. JX: contributed to the conception, draft writing, review and editing. XL: validation, data curation, project administration. QX: writing, review and editing, supervision. All authors read and approved the final manuscript.

\section{Funding}

Not applicable.

Availability of data and materials

Datasets supporting conclusions of this article are included within the article.

\section{Declarations}

\section{Ethics approval and consent to participate}

This study was approved by the Ethics Committee of Sun Yat-sen Memorial Hospital, Sun Yat-sen University. We were exempted from obtaining informed consent because this was a secondary analysis of previously published studies.

\section{Consent for publication}

Written informed consent for publication was obtained from all participants.

\section{Competing interests}

The authors declare that they have no competing interests.

\section{Author details}

${ }^{1}$ Department of Gynecological Oncology, Sun Yat-Sen Memorial Hospital, Sun Yat-Sen University, 107 Yan Jiang Rd West, Guangzhou 510120, People's Republic of China. ${ }^{2}$ Department of Radiology, Sun Yat-Sen Memorial Hospital, Sun Yat-Sen University, 107 Yan Jiang Rd West, Guangzhou 510120, People's Republic of China.

Received: 23 May 2021 Accepted: 17 October 2021

Published online: 29 October 2021

\section{References}

1. Norris HJ, Parmley T. Mesenchymal tumors of the uterus. Intravenous leiomyomatiosis: a clinical and pathologic study of 14 cases. Cancer. 1975: 2164-2178.

2. Gawne-Cain ML, Wilson AG, Corbishley C, Keating V, Joseph AE. Case report: Intravenous leiomyomatosis, an unusual cause of intracardiac filling defect. Clin Radiol. 1995;50:123-5.

3. Shi T, Shkrum MJ. A case report of sudden death from intracardiac leiomyomatosis. Am J Forensic Med Pathol. 2018;39:119-22.

4. Bahary CM, Gorodeski IG, Nilly M, Neri A, Avidor I, Garti IJ. Intravascular leiomyomatosis. Obstet Gynecol. 1982;59:s73-77.

5. Konishi H, Koh I, Shiroma N, Kidani Y, Urabe S, Tanaka N, et al. Two case reports of intravenous leiomyomatosis with hyaluronan expression. Case Rep Obstet Gynecol. 2018;2018:4039183.

6. Su Q, Zhang X, Zhang H, Liu Y, Dong Z, Li G, et al. Intravenous leiomyomatosis of the uterus: a retrospective single-center study in 14 cases. BioMed Res Int. 2020: 1-14.

7. Nili M, Liban E, Levy MJ. Tricuspid stenosis due to intravenous leiomyomatosis-a call for caution: case report and review of the literature. Tex Heart Inst J. 1982: 231-235.

8. Luo G, Pan H, Bi J, Luo Y, Zhu J, Feng Z, et al. Surgical treatment of intravenous leiomyomatosis involving the right heart: a case series. J Int Med Res. 2019:47:3465-74.

9. Kaur S, Tongaonkar HB, Maheshwari A, Menon S. A rare case of recurrent intravenous leiomyomatosis: role of $\mathrm{GnRH}$ analogues? Indian J Cancer. 2015;52:161.

10. Yu X, Zhang G, Lang J, Liu B, Zhao D. Factors associated with recurrence after surgical resection in women with intravenous leiomyomatosis. Obstet Gynecol. 2016;5:1018-24. 
11. Gan HL, Zhang JQ, Zhou QW, Kong QY, Zhao S, Bo P. Surgical treatment of intracardiac leiomyomatosis. J Thorac Cardiovasc Surg. 2011;142:823-8.

12. Zhang G, Yu X, Shi H, Fan Q, Lang J, Liu B. Clinical characteristics and prognostic features of intravenous leiomyomatosis with inferior vena cava or intracardiac extension. J Vasc Surg Venous Lymphat Disord. 2017;5:485-92.

13. Zhang H, Miao Q, Liu J, Wang C, Zhang C, Zhai H. Giant intravenous leiomyomatosis with intracardiac extension. Ann Thorac Surg. 2012;94:1013.

14. Nam MS, Jeon MJ, Kim YT, Kim JW, Park KH, Hong YS. Pelvic leiomyomatosis with intracaval and intracardiac extension: a case report and review of the literature. Gynecol Oncol. 2003;89:175-80.

15. Mitsuhashi A, Nagai Y, Sugita M, Nakajima N, Sekiya S. GnRH agonist for intravenous leiomyomatosis with cardiac extension. A case report. J Reprod Med. 1999;10:883-6.

16. Okamura H, Yamaguchi A, Kimura N, Adachi K, Adachi H. Partial resection of intravenous leiomyomatosis with cardiac extension. Gen Thorac Cardiovasc Surg. 2011;59:38-41.

17. Price JD, Anagnostopoulos C, Benvenisty A, Kothuru RK, Balaram SK. Intracardiac extension of intravenous leiomyomatosis. Ann Thorac Surg. 2017: e145-147.

18. Ma G, Miao Q, Liu X, Zhang C, Liu J, Zheng Y, et al. Different surgical strategies of patients with intravenous leiomyomatosis. Medicine. 2016; 95: e4902.

19. Lam PM, Lo KW, Yu MM, Lau TK, Cheung TH. Intravenous leiomyomatosis with atypical histologic features: a case report. Int J Gynecol Cancer. 2003;13:83-7.

20. Kim JH, Baek JH. A challenging case of intracardiac leiomyomatosis accompanied by pseudo-meigs syndrome originating from uterine leiomyoma. Ann Vasc Surg. 2018:55:e5-8.

21. Kullo IJ, Oh JK, Keeney GL, Khandheria BK, Seward JB. Intracardiac leiomyomatosis echocardiographic features. Chest. 1999:115:587-91.

22. Liu B, Liu C, Guan H, Li Y, Song X, Shen K, et al. Intravenous leiomyomatosis with inferior vena cava and heart extension. J Vasc Surg. 2009;50:897-902.

23. Suginami H, Kaura R, Ochi H, Matsuura S. Intravenous leiomyomatosis with cardiac extension: successful surgical management and histopathologic study. Obstet Gynecol. 1990;3:527-9.

24. Yu HY, Tsai HE, Chi NH, Kuo KT, Wang SS, Chen CA, et al. Long-term outcomes of surgical treatment for intravascular leiomyomatosis. J Formos Med Assoc. 2018;117:964-72.

25. Gehr NR, Lund O, Alstrup P, Nielsen JS, Villadsen AB, Bartholdy NJ. Recurrence of uterine intravenous leiomyomatosis with intracardiac extension. Scand Cardiovasc J. 1999;33:312-4.

26. Park SY, Yeo IH, Kim YJ, Kim JK. Obstruction of the hepatic venous flow caused by intravenous leiomyomatosis. Medicina (Kaunas). 2020;56:696.

27. Lo KW, Lau TK. Intracardiac leiomyomatosis: case report and literature review. Arch Gynecol Obstet. 2001;264:209-10.

28. Timmis AD, Smallpeice C, Davies AC, Macarthur AM, Gishen P, Jackson G. Intracardiac spread of intravenous leiomyomatosis with successful surgical excision. N Engl J Med. 1980;18:1043-4.

29. Murad MH, Sultan S, Haffar S, Bazerbachi F. Methodological quality and synthesis of case series and case reports. BMJ Evid Based Med. 2018;23:60-3
30. Li H, Xu D, Lu W, Wang C. Complete resection of intracardiac leiomyomatosis through an abdominal approach under peripheral cardiopulmonary bypass. J Thorac Cardiovasc Surg. 2016;152:e91-93.

31. Harris LM, Karakousis CP. Intravenous leiomyomatosis with cardiac extension: tumor thrombectomy through an abdominal approach. J Vasc Surg. 2000;31:1046-51.

32. Loverro G, Nicolardi V, Selvaggi L. GnRH analogues treatment of uterine fibroids. Int J Gynecol Obstet. 1993;43:199-201.

33. Ricci MA, Cloutier LM, Mount S, Welander C, Leavitt BJ. Intravenous leiomyomatosis with intracardiac extension. Cardiovasc Surg. 1995;3:693-6.

34. Khayata GM, Thwaini S, Aswad SG. Intravenous leiomyomatosis extending to the heart. Int I Gynecol Obstet. 2003;80:59-60.

35. Judson I, Messiou C. Vitamin D deficiency in the pathogenesis of leiomyoma and intravascular leiomyomatosis: a case report and review of the literature. Gynecol Oncol Rep. 2021;35: 100681

36. Morice P, Chapelier A, Dartevelle P, Castaigne D, Lhommé C. Late intracaval and intracardiac leiomyomatosis following hysterectomy for benign myomas treated by surgery and GnRH agonist. Gynecol Oncol. 2001;83:422-3.

37. Zhang G, Yu X, Lang J. Intravenous leiomyomatosis with inferior vena cava or intracardiac extension and concurrent bilateral multiple pulmonary nodules: a report of 2 cases. Medicine. 2016; 95: e4722.

38. Clay TD, Dimitriou J, McNally OM, Russell PA, Newcomb AE, Wilson AM. Intravenous leiomyomatosis with intracardiac extension e a review of diagnosis and management with an illustrative case. Surg Oncol. 2013;22:e44-52.

39. Li H, Xu J, Lin Q, Zhang $Y$, Zhao $Y$, Tong $H$, et al. Surgical treatment strategies for extra-pelvic intravenous leiomyomatosis. Orphanet J Rare Dis. 2020;15:153.

40. Uchida H, Hattori Y, Nakada K, lida T. Successful one-stage radical removal of intravenous leiomyomatosis extending to the right ventricle. Obstet Gynecol. 2004;5:1068-70.

41. Rispoli P, Santovito D, Tallia C, Varetto G, Conforti M, Rinaldi M. A onestage approach to the treatment of intravenous leiomyomatosis extending to the right heart. J Vasc Surg. 2010;52:212-5.

42. Moniaga NC, Randall LM. Uterine leiomyomatosis with intracaval and intracardiac extension. Gynecol oncol case rep. 2012;2:130-2.

43. Tresukosol D, Kudelka AP, Malpica A, Varma DG, Edwards CL, Kavanagh J. Leuprolide acetate and intravascular leiomyomatosis. Obstet Gynecol. 1995;86:688-92.

44. Castagneto GL, Mariano G, Musleh L, Lepiane P, Colasanti M, Meniconi RL, et al. Massive pelvic recurrence of uterine leiomyomatosis with intracavalintracardiac extension: video case report and literature review. BMC Surg. 2017;17:118.

\section{Publisher's Note}

Springer Nature remains neutral with regard to jurisdictional claims in published maps and institutional affiliations.

Ready to submit your research? Choose BMC and benefit from:

- fast, convenient online submission

- thorough peer review by experienced researchers in your field

- rapid publication on acceptance

- support for research data, including large and complex data types

- gold Open Access which fosters wider collaboration and increased citations

- maximum visibility for your research: over 100M website views per year

At BMC, research is always in progress.

Learn more biomedcentral.com/submissions 